\title{
Neuropsychological outcome after unilateral pallidotomy for the treatment of Parkinson's disease
}

Gayle M Rettig, Michele K York, Eugene C Lai, Joseph Jankovic, Joachim K Krauss, Robert G Grossman, Harvey S Levin

\begin{abstract}
Objective-To assess the long term cognitive outcome of unilateral posteroventral pallidotomy (PVP) and the overall efficacy of the surgery.

Methods-Forty two (29 left and 13 right PVP) patients with Parkinson's disease underwent neurological and neuropsychological testing before PVP and at 3 and 12 months after PVP. The neuropsychological testing battery emphasised measures of verbal learning and memory, visuospatial abilities, speed of information processing, executive functioning, and affective functioning.

Results-All patients demonstrated motor improvements after surgery during their off state, and $86 \%$ of patients also showed improvements in motor functioning in their on state. Repeated measures ANOVA showed significant improvements in confrontational naming, visuospatial organisation, and affective functioning 3 months and 12 months after surgery, with inconsistent improvements in executive functioning 12 months post-PVP. Patients demonstrated a transient impairment in verbal memory, with verbal learning performance returning to baseline 12 months post-PVP after a significant decline 3 months after PVP. When three patients with lesions extending outside of the PVP were excluded from the analysis, a decline in verbal fluency performance after PVP was not found to be significant. Differences due to side of lesion placement were not found on any of the cognitive measures.

Conclusions-In the largest long term follow up study reported to date, the cognitive changes found up to a year after PVP are minimal compared with the robust improvements in motor function. The findings highlight the need to investigate the relation between the specific fibre tracts affected by the lesions and cognitive outcome.

(F Neurol Neurosurg Psychiatry 2000;69:326-336)
\end{abstract}

Keywords: Parkinson's disease; posteroventral pallidotomy; neuropsychology; cognition

Recent advances in neurosurgical, radiological, and electrophysiological techniques have made it possible to produce pallidal lesions that result in marked improvement in the motor symp- toms of advanced Parkinson's disease. ${ }^{1-4}$ Unilateral posteroventral pallidotomy (PVP) has proved to be an effective treatment for control of levodopa induced dyskinesias, and to a lesser degree, for amelioration of rigidity, bradykinesia, and tremor. ${ }^{35-7}$ Although the effects of PVP on the motor symptoms of Parkinson's disease have been reported in detail, the long term effects of PVP on cognitive functioning have not been fully evaluated in a large series.

Although several preliminary studies reported few cognitive changes after $\mathrm{PVP}^{8-10}$ investigations into the impact of the side of lesion on outcome have more consistently shown cognitive changes postoperatively. ${ }^{112}$ Riordan et al found a decline in verbal fluency (word generation from specified initial letters) and semantic fluency (word generation from specified categories) after left PVP and a decline in information processing speed, visuospatial construction, and spatial memory after right PVP. ${ }^{11}$ Likewise, Trepanier et al reported that patients with left PVP experienced a decline in verbal learning, verbal fluency, and attentional capacity; whereas the patients with right PVP demonstrated an improvement in verbal learning ability and a transient decline in spatial memory. ${ }^{12}$ Overall, a decline in verbal fluency is the most consistent neuropsychological change after PVP, particularly when lesion laterality is evaluated. ${ }^{9} 13-15$

Several methodological issues complicate interpretation of the current PVP literature. ${ }^{16}$ For example, the use of large neuropsychological batteries with small sample sizes results in a greater chance of not detecting significant differences, the limited reporting of attrition rates limits the generalisability of the findings, and the limited reporting of postoperative MRI findings limits the conclusions that can be drawn about the relation between lesion size and cognitive outcome. ${ }^{8101415}$ Thus, it is difficult to determine if the conclusions garnered from these studies are based on representative samples that adequately reflect the entire population of patients with PVP.

Although PVP related motor improvements have been reported to be maintained for up to 4 years after surgery, the cognitive effects of the PVP have been described preliminarily for only up to 12 months post-PVP. ${ }^{5}{ }^{12}$ It is essential to assess thoroughly the long term cognitive outcome of PVP to fully appreciate the overall efficacy of the surgery. To address the aforementioned methodological limitations, we report the cognitive domains affected by right 
Table 1 Demographics of pallidotomy patients with preoperative, 3 month, and 1 year follow up evaluations $(n=42) *$

\begin{tabular}{|c|c|c|c|c|c|c|}
\hline & \multicolumn{2}{|l|}{ Right $(n=13)$} & \multicolumn{2}{|l|}{ Left $(n=29)$} & \multicolumn{2}{|l|}{ Total $(n=42)$} \\
\hline & Mean (SD) & $\%$ & Mean (SD) & $\%$ & Mean (SD) & $\%$ \\
\hline \multicolumn{7}{|l|}{ Sex: } \\
\hline Male & & 54 & & 55 & & 55 \\
\hline Female & & 46 & & 45 & & 45 \\
\hline Age $(y)$ & $58.2(9.7)$ & & $61.6(9.4)$ & & $60.8(9.4)$ & \\
\hline Education (y) & $13.3(4.3)$ & & $13.5(2.3)$ & & $13.2(2.5)$ & \\
\hline Age of onset (y) & $45.9(10.7)$ & & $46.5(9.8)$ & & $46.3(9.9)$ & \\
\hline Duration (y) & $13.3(4.3)$ & & $15.1(5.5)$ & & $14.5(5.2)$ & \\
\hline MMSE & $28.4(1.5)$ & & $27.7(2.25)$ & & $27.9(2.1)$ & \\
\hline Levodopa (mg) & $481(306)$ & & $463(212)$ & & $468(241)$ & \\
\hline Hoehn and Yahr"on" & $2.7(.60)$ & Range $1-4$ & $2.6(.75)$ & Range $1-4$ & $2.7(.12)$ & Range $1-4$ \\
\hline Hoehn and Yahr"off" & $4.0(.71)$ & Range 3-5 & $4.0(.66)$ & Range 3-5 & $4.0(.11)$ & Range 3-5 \\
\hline
\end{tabular}

${ }^{\star}$ No significant differences were found between right and left pallidotomy patients on demographic variables.

and left PVP in a sample of 42 patients at 3 months and 12 months after PVP.

\section{Method}

SUBJECTS

Patients were considered eligible for PVP if: (1) their clinical findings were consistent with idiopathic Parkinson's disease; (2) they had a history of response to levodopa therapy; and (3) they had evidence of advanced disease (disabling motor fluctuations, levodopa induced dyskinesias, or freezing, and a Hoehn and Yahr Parkinson's disease staging score of 3 or more during their off period).$^{17}{ }^{18}$ Patients were excluded if they: (1) had mini mental state examination (MMSE) scores less than 20; (2) were 76 years or older; (3) had psychiatric complications that might interfere with compliance (for example, psychosis, severe major depression); or (4) had a Hoehn and Yahr score of 5 during their "on" period. ${ }^{19}$ The patients were followed up at the Baylor College of Medicine Parkinson's Disease Center and Movement Disorders Clinic and were maintained on an optimal level of anti-Parkinson's medication for at least 1 month before PVP. ${ }^{18}$

The first 42 consecutive patients who underwent neuropsychological testing preoperatively, and at 3 months and 12 months post-PVP were included in the study. Table 1 describes relevant patient characteristics at the baseline evaluation for patients with right or left PVP. All 42 patients (23 men and 19 women) were right handed and had advanced idiopathic Parkinson's disease based on clinical symptoms and neurological examination. The patients with right or left PVP did not differ significantly from each other on any demographic or neurological variables. Two patients who had had a previous neurosurgical procedure before PVP were included in the analyses to capture a representative sample of patients with PVP. One patient had had an adrenal implant to the right caudate nucleus nine years before his PVP; the second patient had had a left frontal ventriculoperitoneal shunt for hydrocephalus due to aqueductal stenosis, 10 years before PVP.

\section{PROCEDURES}

Surgical procedure

Pallidotomy was performed contralateral to the side of the body most affected by motor symptoms. Most patients showed more severe motor symptoms on the right side. If both sides of the body were similarly affected, the patients most often chose to have left PVP to alleviate symptoms on their dominant side. Both of these factors resulted in a larger number of left sided operations (29 left $v 13$ right PVP).

Stereotactic CT guidance, microelectrode recording, and macrostimulation were used to determine the optimal site of the lesion within the internal segment of the globus pallidus (GPi). The coordinates of the lesion were 19-21 mm lateral, $4-5 \mathrm{~mm}$ below, and $2-3 \mathrm{~mm}$ anterior to the midpoint of the intercommissural line. ${ }^{20}$ In general, two lesions spaced 1.5 to $2.0 \mathrm{~mm}$ apart were created with the temperature controlled at $75^{\circ} \mathrm{C}$ for 60 seconds. A detailed description of the procedure has been published elsewhere. ${ }^{21}$

\section{Neurological evaluation}

Patients were evaluated using a modified core assessment program for intracerebral transplantation protocol (CAPIT), including the unified Parkinson's disease rating scale (UPDRS), the Hoehn and Yahr staging scale, the Schwab and England activities of daily living scale, and additional examinations. ${ }^{17}{ }^{22}$ All formal clinical evaluations were performed by movement disorder specialists. Patients were examined in their off and "on" states. A detailed description of the neurological evaluations has been presented elsewhere. ${ }^{18}$

\section{Neuropsychological evaluation}

The neuropsychological test battery was selected to assess the pattern of cognitive deficits previously shown to be impaired in advanced Parkinson's disease. ${ }^{23} 24$ The evaluation was conducted while the patients were in their best on state, a condition that might have fluctuated during the 3 hour testing period. The patients took their scheduled dosage of medications throughout testing. Standardised test administration procedures were used. The examiners were not blinded to the patient's surgical status. Table 2 describes the neuropsychological measures by cognitive domain. The testing battery emphasised measures of verbal learning and memory, visuospatial abilities, speed of information processing, executive functioning, and affective functioning.

STATISTICAL METHODS

Repeated measures analyses of variance (ANOVAs) with time (baseline, 3 months, 12 
months) as the within subject factor and lesion side (right versus left) as the between subject factor were performed for each of the neurological, neuropsychological, and affective measures. Main effects of time and lesion side and the timexlesion side interaction effect were evaluated. Simple (preoperative to 3 months, preoperative to 12 months), and Helmert (3 to 12 months) contrasts were conducted for each significant time main effect to determine the source of the significant difference. Due to the number of contrasts performed on the significant time main effects, type I error may have been increased; therefore, caution should be exercised when interpreting the results of the contrasts. The $\alpha$ level was set at 0.05 for all analyses. The effect size, or partial $\varepsilon^{2}$, was calculated for each significant finding to help evaluate the proportion of variance accounted for by the cognitive variable.

A second set of repeated measures ANOVAs were run for each neuropsychological variable using standardised scores as the dependent measure. Published test norms were used to obtain standardised $\mathrm{z}$ scores and percentile scores. The results of these analyses were similar to the original repeated measures ANOVAs using raw scores; therefore, only the analyses using the raw data will be reported.

There were missing data for several of the neuropsychological measures in some patients due to: (1) the patient's inability to perform a task, (2) a change in the neuropsychological testing battery early in the study, or (3) the test not being given. If a patient was unable to perform a task for cognitive reasons, the lowest score for that task and time point was assigned. This assignment occurred for three patients on the COWAT, one patient on the WCST, and two patients on the SymDigit (table 2). Ten patients had missing data due to procedural changes on the WCST and seven patients had missing data on the CVLT. Therefore, the analyses with these variables were run with 32 (10 right and 22 left PVP) and 35 patients (11 right and 24 left PVP), respectively. One way ANOVA showed that the patients with missing data on the WCST and CVLT did not differ from the other patients on any of the demographic variables.

\section{Attrition rates}

The attrition rate for the entire sample of patients who underwent PVP $(n=79)$ from the baseline to the 3 month evaluation was $20 \%$ (16 patients) and from the 3 month to 12 month evaluation was $27 \%$ (21 patients). The moderate attrition rates were due to numerous factors including: travel distance, scheduling conflicts, and difficulties in cooperation. The 42 study participants did not differ significantly on any demographic variable from the 37 patients who did not complete all three testing evaluations. At baseline evaluation, the study participants reported fewer symptoms of depression (study: mean=10.2 (SD 7.0) $v$ drop outs: mean $=14.2($ SD 7.9); $\mathrm{p}=0.02)$ and scored slightly higher on the MMSE (study: mean $=27.9$ (SD 2.1) $v$ drop outs: mean $=26.2$ (SD 3.8), $\mathrm{p}=0.02$ ) than those patients lost to follow up. Furthermore, the study participants differed significantly from the drop outs on the UPDRS total scores (study: mean $=45.2$ (SD 12.7) $v$ drop outs: mean $=52.5($ SD 12.8)) and the Schwab and England scores (study: mean $=76.3$, (SD 11.4) $v$ drop outs: mean $=70.8$ (SD 12.4)) while in the on state before PVP. However, no significant differences were found between study participants and those patients who did not complete both follow up evaluations on the neurological measures while in the off state.

\section{Results}

NEUROLOGICAL MEASURES

Baseline

Table 3 shows the means (SD) for the baseline neurological measures for the patients with right or left PVP. Overall, before surgery, patients demonstrated minimally to moderately severe motor disability during the on state, (Hoehn and Yahr: mean=2.66 (SD 0.12); UPDRS: mean=46.2 (SD 2.0)), with severe disability during the off state (Hoehn and Yahr: mean=4.00 (SD 0.12); UPDRS: mean=87.1 (SD 3.0)). During the on state, patients reported mild limitations in their

Table 2 Neuropsychological measures by cognitive domain

\begin{tabular}{|c|c|}
\hline Cognitive domain & Description and key variable measured \\
\hline \multicolumn{2}{|l|}{ Mental status: } \\
\hline Mini mental state exam (MMSE) ${ }^{19}$ & Orientation and mental status; total score \\
\hline \multicolumn{2}{|l|}{ Verbal learning and memory: } \\
\hline California verbal learning test $(\mathrm{CVLT})^{25}$ & $\begin{array}{l}\text { New learning and recall of a list of } 16 \text { categorised words; total 1-5 (sum of words recalled on five free recall trials); long } \\
\text { delay (number of words recalled after a } 20 \text {-minute filled delay) }\end{array}$ \\
\hline \multicolumn{2}{|r|}{ 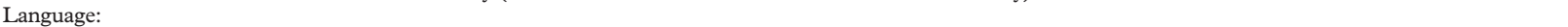 } \\
\hline Boston naming test $(\mathrm{BNT})^{26}$ & Confrontational naming; total (number of drawings named correctly or with the aid of semantic cueing) \\
\hline Verbal fluency test (COWAT) ${ }^{27}$ & Phonemic fluency; total (words generated in 60 seconds for each of three letters) \\
\hline \multicolumn{2}{|l|}{ Visuospatial ability: } \\
\hline Hooper visual organisation (Hooper) ${ }^{28}$ & Visuospatial organisation; total (number of pictures identified) \\
\hline \multicolumn{2}{|l|}{ Information processing speed: } \\
\hline Trail making test part $\mathrm{A}(\text { trailsA) })^{29}$ & Speed and accuracy of visuospatial tracking; total time to completion (seconds) \\
\hline Symbol digit modalities test $(\mathrm{SDMT})^{30}$ & Oral rate of information processing in a visual task; total (number of symbols transcribed in 90 seconds) \\
\hline \multicolumn{2}{|r|}{ 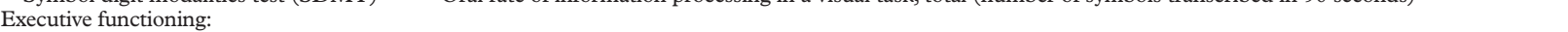 } \\
\hline Wisconsin card sorting test (WCST) ${ }^{31}$ & $\begin{array}{l}\text { Generating hypotheses and abstract concepts, shifting mental sets, and utilising feedback; categories (number of } \\
\text { categories achieved), perseverative errors (persistence in responding to an incorrect concept), and total error (number of } \\
\text { perseverative and non-perseverative errors) }\end{array}$ \\
\hline Stroop colour word test (Stroop) $)^{32}$ & $\begin{array}{l}\text { Mental flexibility and the ability to suppress a preferred response in favour of a competing novel response; interference } \\
\text { (index of the ability to resist interference from competing stimuli) }\end{array}$ \\
\hline Trail making test part $\mathrm{B}$ (trailsB) ${ }^{29}$ & Mental flexibility and visuospatial tracking; total time to completion (seconds) \\
\hline \multicolumn{2}{|l|}{ Affective functioning: } \\
\hline Beck depression inventory $(\mathrm{BDI})^{33}$ & Depressive symptoms; total score \\
\hline
\end{tabular}


Table 3 Repeated measures ANOVA results for neurological measurest $\neq S$

\begin{tabular}{|c|c|c|c|c|c|c|c|c|c|c|c|}
\hline \multirow[b]{2}{*}{ Measure } & \multicolumn{3}{|c|}{ Pre-PVP } & \multicolumn{3}{|c|}{3 month Post-PVP } & \multirow[b]{2}{*}{$\begin{array}{l}\text { Pre to } 3 \\
\text { months } p \\
\text { Value }\end{array}$} & \multicolumn{3}{|c|}{12 month Post-PVP } & \multirow[b]{2}{*}{$\begin{array}{l}\text { Pre to } 12 \\
\text { months } p \\
\text { Value }\end{array}$} \\
\hline & $\begin{array}{l}\text { Right } \\
\text { Mean } \\
\text { (SD) }\end{array}$ & $\begin{array}{l}\text { Left } \\
\text { Mean } \\
(S D)\end{array}$ & $\begin{array}{l}\text { Total } \\
\text { Mean } \\
\text { (SD) }\end{array}$ & $\begin{array}{l}\text { Right } \\
\text { Mean } \\
\text { (SD) }\end{array}$ & $\begin{array}{l}\text { Left } \\
\text { Mean } \\
(S D)\end{array}$ & $\begin{array}{l}\text { Total } \\
\text { Mean } \\
\text { (SD) }\end{array}$ & & $\begin{array}{l}\text { Right Mean } \\
(S D)\end{array}$ & $\begin{array}{l}\text { Left } \\
\text { Mean } \\
(S D)\end{array}$ & $\begin{array}{l}\text { Total } \\
\text { Mean } \\
\text { (SD) }\end{array}$ & \\
\hline \multicolumn{12}{|l|}{$\mathrm{H}$ and $\mathrm{Y}$ staging $(\mathrm{I}-\mathrm{V})$} \\
\hline On & $\begin{array}{l}2.69 \\
(0.60)\end{array}$ & $\begin{array}{l}2.62 \\
(0.75)\end{array}$ & $\begin{array}{l}2.66 \\
(0.12)\end{array}$ & $\begin{array}{l}1.69 \\
(0.66)\end{array}$ & $\begin{array}{l}1.79 \\
(0.76)\end{array}$ & $\begin{array}{l}1.74 \\
(0.12)\end{array}$ & $0.01^{\star \star}$ & $\begin{array}{l}1.73 \\
(0.97)\end{array}$ & $\begin{array}{l}1.78 \\
(0.74)\end{array}$ & $\begin{array}{l}1.75 \\
(0.14)\end{array}$ & $0.01^{\star \star}$ \\
\hline Off & $\begin{array}{l}4.00 \\
(0.71)\end{array}$ & $\begin{array}{l}4.00 \\
(0.66)\end{array}$ & $\begin{array}{l}4.00 \\
(0.12)\end{array}$ & $\begin{array}{l}2.65 \\
(0.56)\end{array}$ & $\begin{array}{l}2.85 \\
(0.70)\end{array}$ & $\begin{array}{l}2.75 \\
(0.11)\end{array}$ & $0.01^{\star \star}$ & $\begin{array}{l}2.65 \\
(0.56)\end{array}$ & $\begin{array}{l}3.02 \\
(0.75)\end{array}$ & $\begin{array}{l}2.84 \\
(0.12)\end{array}$ & $0.01^{\star \star}$ \\
\hline \multicolumn{12}{|l|}{ UPDRS Total (0-199) } \\
\hline On & $\begin{array}{l}46.8 \\
(9.0)\end{array}$ & $\begin{array}{l}44.4 \\
(14.1)\end{array}$ & $\begin{array}{l}46.2 \\
(2.0)\end{array}$ & $\begin{array}{l}20.6 \\
(6.0)\end{array}$ & $\begin{array}{l}23.9 \\
(11.1)\end{array}$ & $\begin{array}{l}22.3 \\
(1.6)\end{array}$ & $0.01^{\star \star}$ & $\begin{array}{l}21.6 \\
(9.8)\end{array}$ & $\begin{array}{l}23.7 \\
(10.7)\end{array}$ & $\begin{array}{l}22.9 \\
(1.7)\end{array}$ & $0.01^{\star \star}$ \\
\hline Off & $\begin{array}{l}88.2 \\
(19.2)\end{array}$ & $\begin{array}{l}85.9 \\
(17.5)\end{array}$ & $\begin{array}{l}87.1 \\
(3.0)\end{array}$ & $\begin{array}{l}47.6 \\
(12.2)\end{array}$ & $\begin{array}{l}50.9 \\
(15.7)\end{array}$ & $\begin{array}{l}49.3 \\
(2.5)\end{array}$ & $0.01^{\star \star}$ & $\begin{array}{l}47.0 \\
(11.4)\end{array}$ & $\begin{array}{l}52.1 \\
(14.7)\end{array}$ & $\begin{array}{l}49.5 \\
(2.3)\end{array}$ & $0.01^{\star \star}$ \\
\hline \multicolumn{12}{|l|}{ UPDRS Motor (0-144) } \\
\hline On & $\begin{array}{l}29.5 \\
(8.1)\end{array}$ & $\begin{array}{l}28.8 \\
(10.7)\end{array}$ & $\begin{array}{l}29.1 \\
(1.7)\end{array}$ & $\begin{array}{l}13.8 \\
(4.8)\end{array}$ & $\begin{array}{l}15.4 \\
(8.9)\end{array}$ & $\begin{array}{l}14.6 \\
(1.3)\end{array}$ & $0.01^{\star \star}$ & $\begin{array}{l}14.7 \\
(8.0)\end{array}$ & $\begin{array}{l}14.8 \\
(7.0)\end{array}$ & $\begin{array}{l}14.8 \\
(1.2)\end{array}$ & $0.01^{\star \star}$ \\
\hline Off & $\begin{array}{l}55.6 \\
(16.3)\end{array}$ & $\begin{array}{l}55.0 \\
(13.1)\end{array}$ & $\begin{array}{l}55.3 \\
(2.4)\end{array}$ & $\begin{array}{l}31.8 \\
(9.2)\end{array}$ & $\begin{array}{l}32.6 \\
(11.4)\end{array}$ & $\begin{array}{l}32.2 \\
(1.8)\end{array}$ & $0.01^{\star \star}$ & $\begin{array}{l}30.5 \\
(8.1)\end{array}$ & $\begin{array}{l}33.3 \\
(11.1)\end{array}$ & $\begin{array}{l}31.9 \\
(1.7)\end{array}$ & $0.01^{\star \star}$ \\
\hline \multicolumn{12}{|l|}{ UPDRS ADL (0-51) } \\
\hline On & $\begin{array}{l}15.5 \\
(4.4)\end{array}$ & $\begin{array}{l}15.7 \\
(4.8)\end{array}$ & $\begin{array}{l}15.6 \\
(0.78)\end{array}$ & $\begin{array}{l}7.15 \\
(4.0)\end{array}$ & $\begin{array}{l}7.90 \\
(3.7)\end{array}$ & $\begin{array}{l}7.53 \\
(0.63)\end{array}$ & $0.01^{\star \star}$ & $\begin{array}{l}6.85 \\
(2.8)\end{array}$ & $\begin{array}{l}8.07 \\
(3.4)\end{array}$ & $\begin{array}{l}7.46 \\
(0.53)\end{array}$ & $0.01^{\star \star}$ \\
\hline Off & $\begin{array}{l}29.6 \\
(6.7)\end{array}$ & $\begin{array}{l}30.9 \\
(5.7)\end{array}$ & $\begin{array}{l}30.3 \\
(1.0)\end{array}$ & $\begin{array}{l}16.2 \\
(5.7)\end{array}$ & $\begin{array}{l}18.3 \\
(5.4)\end{array}$ & $\begin{array}{l}17.3 \\
(0.91)\end{array}$ & $0.01^{\star \star}$ & $\begin{array}{l}16.2 \\
(3.7)\end{array}$ & $\begin{array}{l}18.6 \\
(4.8)\end{array}$ & $\begin{array}{l}17.4 \\
(0.75)\end{array}$ & $0.01^{\star \star}$ \\
\hline \multicolumn{12}{|l|}{$S$ and $\mathrm{E}$ ADL $(0 \%-100 \%)$} \\
\hline On & $\begin{array}{l}78.5 \\
(8.0)\end{array}$ & $\begin{array}{l}75.3 \\
(12.6)\end{array}$ & $\begin{array}{l}76.9 \\
(1.9)\end{array}$ & $\begin{array}{l}89.6 \\
(8.0)\end{array}$ & $\begin{array}{l}89.1 \\
(7.1)\end{array}$ & $\begin{array}{l}89.4 \\
(1.2)\end{array}$ & $0.01^{\star \star}$ & $\begin{array}{l}87.7 \\
(12.5)\end{array}$ & $\begin{array}{l}89.3 \\
(7.0)\end{array}$ & $\begin{array}{l}88.5 \\
(1.5)\end{array}$ & $0.01^{\star \star}$ \\
\hline Off & $\begin{array}{l}43.1 \\
(13.2)\end{array}$ & $\begin{array}{l}44.5 \\
(14.3)\end{array}$ & $\begin{array}{l}43.8 \\
(2.3)\end{array}$ & $\begin{array}{l}67.3 \\
(10.5)\end{array}$ & $\begin{array}{l}63.6 \\
(16.8)\end{array}$ & $\begin{array}{l}65.5 \\
(2.5)\end{array}$ & $0.01^{\star \star}$ & $\begin{array}{l}66.9 \\
(10.3)\end{array}$ & $\begin{array}{l}60.1 \\
(15.4)\end{array}$ & $\begin{array}{l}63.5 \\
(2.4)\end{array}$ & $0.01^{\star \star}$ \\
\hline $\begin{array}{l}\text { Levodopa total daily dose } \\
\text { (mg) }\end{array}$ & $\begin{array}{l}481 \\
(306)\end{array}$ & $\begin{array}{l}463 \\
(212)\end{array}$ & $\begin{array}{l}468 \\
(241)\end{array}$ & $\begin{array}{l}587 \\
(329)\end{array}$ & $\begin{array}{l}500 \\
(315)\end{array}$ & $\begin{array}{l}526 \\
(318)\end{array}$ & 0.19 & $\begin{array}{l}613 \\
(368)\end{array}$ & $\begin{array}{l}515 \\
(406)\end{array}$ & $\begin{array}{l}545 \\
(393)\end{array}$ & 0.16 \\
\hline
\end{tabular}

$†$ No significant differences between right and left pallidotomy patients on neurological variables; $\ddagger$ time factor significant at $\mathrm{p}<0.01$ for all variables unless noted; $₫ 3$ months did not differ significantly from 12 months on any neurology measure; $₫ p<0.18$.

$\mathrm{ADL}=$ Activities of daily living; $\mathrm{H}$ and $\mathrm{Y}=\mathrm{Hoehn}$ and Yahr staging, higher number indicates more impairment; $\mathrm{S}$ and $\mathrm{E}=\mathrm{Schwab}$ and England activities of daily living scale, higher number indicates more independence; UPDRS=united Parkinson's disease rating scale, higher number indicates more impairment.

ability to perform activities of daily living (ADLs) (UPDRS ADL: mean $=15.6$ (SD 0.78); Schwab and England: mean $=76.9 \%$ (SD 1.9)), while they required moderate to total assistance during the off state (UPDRS ADL: mean=30.3 (SD 1.0); Schwab and England: mean $=43.8 \%$ (SD 2.3)). Preoperative mean total daily dose of levodopa was $468 \mathrm{mg}$ (SD 241) (range $=50$ to $1000 \mathrm{mg}$ ).

\section{Outcome}

Table 3 shows the means (SD) for the neurological measures at the baseline, 3 month follow up, and 12 month follow up evaluations for the patients with right or left PVP in the on and off states. Overall, patients with right or left PVP demonstrated significant improvements in Hoehn and Yahr staging, UPDRS total score, and UPDRS motor score in the on and off states between the baseline and the 3 month and the 12 month follow up evaluations $(\mathrm{p}=0.01)$. The 3 and 12 month evaluations did not differ significantly from each other on any of these measures ( Hoehn and Yahr: on, $\mathrm{p}=0.90$, off $\mathrm{p}=0.31$; UPDRS: on $\mathrm{p}=0.61$, off $\mathrm{p}=0.85$; UPDRS motor: on $\mathrm{p}=0.88$, off $\mathrm{p}=0.79)$. Three months after PVP, $100 \%$ of patients showed motor improvements while in the off state, while $86 \%$ of patients showed motor improvements while in the on state. Between the 3 month and 12 month assessments, three patients showed a 10 point decline in UPDRS scores while on (95\% maintained improvements from 3 months, $n=39$ ), and four patients showed a 10 point decline in UPDRS scores while off $(90 \%$ maintained improvements from 3 months, $n=38$ ).

Furthermore, patients with right or left PVP experienced overall significant improvements in UPDRS ADL scores, and Schwab and England scores in the on and off states post-PVP $(\mathrm{p}=0.01)$. The 3 month and 12 month evaluations did not differ significantly from each other on either of these measures (UPDRS ADL: on $p=0.81$; off $p=0.71$; Schwab and England: on $\mathrm{p}=0.34$, off $\mathrm{p}=0.25$ ). Three months after PVP, $74 \%$ of patients showed more than a 10 point improvement in Schwab and England scores while on, whereas 88\% reported improvements in their ability to perform ADLs independently while in the off state. Between the 3 month and 12 month follow up evaluations, two patients showed a decline ( $\geqslant 10$ point decline in Schwab and England scores) in their ability to perform ADLs independently in the on state $(95 \%$ maintained improvements from 3 months), whereas 16 patients demonstrated declines $(\geqslant 10$ point decline in Schwab and England scores) in their ADL ability in the off state (61\% maintained improvements from 3 months). In general, improvements in the patients' motor functioning and ability to perform ADLs were maintained for up to 1 year after PVP. These improvements were achieved while most patients were maintained on their pre-PVP mean total daily dose of levodopa ( $\mathrm{p}=0.18$; table 3$)$ and there was not a significant change in other anti-parkinsonian drugs.

\section{LESION VERIFICATION}

The size and location of the PVP lesion was investigated 1 to 3 days postoperatively and at a 6 month follow up evaluation by MRI studies. A detailed description of the MRI procedure has been published elsewhere. ${ }^{34}$ In the early phase and late phase images, the lesion 
Table 4 Scores for neuropsychology measures that declined after PVP for three patients with adverse events on postoperative imaging studies ${ }^{\star}+$

\begin{tabular}{|c|c|c|c|c|c|c|c|c|c|}
\hline \multirow[b]{2}{*}{ Measure } & \multicolumn{3}{|l|}{ Patient 1} & \multicolumn{3}{|l|}{ Patient 2} & \multicolumn{3}{|l|}{ Patient 3} \\
\hline & $\begin{array}{l}\text { Pre } \\
\text { Raw }(S D) \neq\end{array}$ & $\begin{array}{l}3 \text { months } \\
\text { Raw (SD) }\end{array}$ & $\begin{array}{l}12 \text { months } \\
\text { Raw (SD) }\end{array}$ & $\begin{array}{l}\text { Pre } \\
\text { Raw (SD) }\end{array}$ & $\begin{array}{l}3 \text { months } \\
\text { Raw (SD) }\end{array}$ & $\begin{array}{l}\text { 12months } \\
\text { Raw (SD) }\end{array}$ & $\begin{array}{l}\text { Pre } \\
\text { Raw (SD) }\end{array}$ & $\begin{array}{l}3 \text { months } \\
\operatorname{Raw}(S D)\end{array}$ & $\begin{array}{l}12 \text { months } \\
\text { Raw (SD) }\end{array}$ \\
\hline MMSE & 28 & $\begin{array}{l}28 \\
24(-3.2)\end{array}$ & $\begin{array}{l}27 \\
22(-3.4)\end{array}$ & 27 & $\begin{array}{l}27 \\
30(-2.8)\end{array}$ & $\begin{array}{l}29 \\
31(-2.2)\end{array}$ & 29 & 26 & 27 \\
\hline CVLT Total & $29(-2.1)$ & $\begin{array}{l}\downarrow-1.1 \\
20(-1.7)\end{array}$ & $\begin{array}{l}\downarrow-1.3 \\
18(-2.0)\end{array}$ & $39(-1.2)$ & $\begin{array}{l}\downarrow-1.6 \\
26(-1.2)\end{array}$ & $\begin{array}{l}\downarrow-1.0 \\
19(-2.0)\end{array}$ & $61(0.60)$ & $53(-0.30)$ & $52(-0.40)$ \\
\hline COWAT & $28(-0.30)$ & $\begin{array}{l}\downarrow-1.4 \\
24(-3.4)\end{array}$ & $\begin{array}{l}\downarrow-1.7 \\
21(-3.8)\end{array}$ & $43(0.60)$ & $\begin{array}{l}\downarrow-1.8 \\
25(-3.3)\end{array}$ & $\downarrow-2.6$ & $19(-0.68)$ & $18(-0.72)$ & $21(-0.40)$ \\
\hline SDMT & $35(-2.2)$ & $\begin{array}{l}\downarrow-1.2 \\
42(-0.65)\end{array}$ & $\begin{array}{l}\downarrow-1.6 \\
55(-1.9)\end{array}$ & $35(-2.2)$ & $\downarrow-1.1$ & $27(-3.1)$ & $30(-2.1)$ & $\begin{array}{l}21(-3.0) \\
80(-3.0)\end{array}$ & $\begin{array}{l}29(-2.2) \\
73(-2.5)\end{array}$ \\
\hline Trails A & $71(-3.5)$ & $\begin{array}{l}\uparrow-2.9 \\
288(-8.0)\end{array}$ & $\begin{array}{l}\uparrow-1.6 \\
257(-6.9)\end{array}$ & $46(-1.3)$ & $48(-1.5)$ & $\begin{array}{l}38(-0.39) \\
200(-4.2)\end{array}$ & $49(-0.64)$ & $\begin{array}{l}\downarrow 2.4 \\
199(-4.1)\end{array}$ & $\downarrow-1.86$ \\
\hline Trails B & $151(-2.8)$ & $\begin{array}{l}\downarrow-5.2 \\
84(-2.5)\end{array}$ & $\downarrow-4.1$ & $147(-2.2)$ & $164(-2.8)$ & $\downarrow-2.0$ & $154(-2.5)$ & $\downarrow-1.6$ & $146(-2.2)$ \\
\hline $\begin{array}{l}\text { WCST Total errors } \\
\text { BDI }\end{array}$ & $\begin{array}{l}59(-1.3) \\
1\end{array}$ & $\downarrow-1.2$ & $\begin{array}{l}72(-2.0) \\
3\end{array}$ & $\begin{array}{l}55(-.57) \\
4\end{array}$ & $\begin{array}{l}61(-0.93) \\
4\end{array}$ & $\begin{array}{l}60(-0.86) \\
8\end{array}$ & $\begin{array}{l}51(-0.95) \\
12\end{array}$ & $\begin{array}{l}51(-0.95) \\
15\end{array}$ & $\begin{array}{l}52(-1.0) \\
6\end{array}$ \\
\hline
\end{tabular}

${ }^{\star}$ BNT, CVLT long delay, Hooper, and Stroop interference did not decline greater than 1 SD for three patients; †see table 2 for description of variables measured; ¥SDs are based on published test norms (see table 2 for references); $\downarrow=$ decline from baseline $\geqslant 1$ SD; $\uparrow=$ improvement from baseline $\geqslant 1$ SD.

was located in the GPi in all instances. The mean volume of the late phase lesions was 22 (SD 28.8) $\mathrm{mm}^{3} .^{34}$

POSTOPERATIVE IMAGING STUDIES

Three study participants had adverse events on postoperative imaging studies. Two patients had small ischaemic infarctions involving the corona radiata, and in one a venous infarction at the entry site of the electrode was detected. These findings were incidental in two patients, but ischaemic infarction resulted in mild transient Broca's aphasia in one instance. Patient 1 was a 62 year old white man with a 15 year history of Parkinson's disease. After left PVP, he had a mild aphasia that was found to be secondary to a small ischaemic infarction involving the corona radiata, the periventricular white matter, and the dorsal thalamus. Patient 2 was a 71 year old white woman who underwent a left PVP to relieve her contralateral motor symptoms. A frontal cortical subcortical venous infarction was detected on the routine postoperative MRI at the entry site of the electrode which, however, was asymptomatic clinically. Patient 3 was a 61 year old white woman who had a right PVP after 8 years of PD. The incidental finding of an asymptomatic small ischaemic infarction extending from the pallidal lesion into the corona radiata was also noted on routine postoperative imaging. Despite these adverse events on postoperative imaging studies all three patients benefited from improvement in their motor function and ADLs up to the 1 year clinical follow up. To determine whether these adverse events on postoperative imaging studies affected cognitive outcome after PVP, the neuropsychological data were analysed a second time excluding these three patients. Significant changes in neuropsychological outcome based on the second analyses are discussed below by cognitive domain (see neuropsychology measures section).

Table 4 shows the neuropsychological measures that demonstrated decline (greater than 1SD) from baseline for the three patients with adverse events on postoperative imaging studies. Patients 1 and 2 showed subtle declines in verbal memory, verbal fluency, information processing, and executive functioning up to 1 year after PVP. Whereas the performance of patient on trails A showed a stable improvement from his baseline testing, his performance on trails B declined, suggesting difficulty with set shifting rather than the motor or information processing aspects of the task. Patient 3 showed more subtle and transient declines after PVP in information processing and executive functioning with an improvement in her affective functioning 1 year after surgery.

\section{NEUROPSYCHOLOGICAL MEASURES}

Baseline

Table 5 shows the means (SD) for the baseline neuropsychological scores for the patients with right or left PVP. When the patients' baseline scores were compared with published norms for age and education matched nonParkinson's disease groups, average to low average performance was shown on confrontational naming (BNT), visuospatial organisation (Hooper), verbal new learning (CVLT total), verbal fluency (COWAT), and mental flexibility (WCST). Information processing tasks (SymDigit, trails A) were borderline impaired and executive functioning tasks requiring a verbal or motor output and switching set or interference (Stroop, trails B) were borderline to mildly impaired. Patients reported a minimal level of depressive symptoms before surgery. This pattern of cognitive impairment is common in patients with Parkinson's disease and suggests involvement of the frontostriatal cognitive system. ${ }^{35}$

\section{Outcome by cognitive domain}

Table 5 shows the means (SD) for the 3 month and 12 month follow up evaluations for the patients with right or left PVP. To distinguish between improvements due to practice effects and improvements due to the effects of surgery, alternate test forms of the CVLT were administered in a counterbalanced fashion. Alternate forms were not available for the remaining tests; therefore, significant improvements in these tests may be due to practice effects and, in the absence of a non-surgical control group, must be viewed with caution. 


\section{Mental status}

No significant differences were found between the baseline, 3 month, and 12 month evaluations on the MMSE $(p=0.91)$ and the timexlesion side interaction effect was nonsignificant $(\mathrm{p}=0.33)$.

\section{Verbal learning}

Between the baseline and 3 month follow up evaluation, patients showed a significant decline in the total number of words recalled over five trials on the CVLT $(p=0.004)$. There was not a significant difference between the baseline and 12 month scores on this measure $(\mathrm{p}=0.42)$; but the 3 month and 12 month scores differed significantly $(\mathrm{p}=0.04)$. The time $\times$ lesion side interaction was not significant $(p=0.73)$. Time accounted for $22 \%$ of the variance in CVLT total scores, which is a moderately large effect size. Patients showed a transient decline in verbal learning and memory at 3 months post-PVP with a return to baseline performance by the 12 month evaluation. When the three patients with adverse events on postoperative imaging studies were excluded from this analysis, the decline in total number of words recalled on the CVLT remained significant but the magnitude decreased from the $\mathrm{p}<0.01$ level to the $\mathrm{p}<0.05$ level. Scores on the CVLT long delay did not differ significantly across time periods $(\mathrm{p}=0.18)$, and the timexlesion side interaction effect was non-significant for CVLT long delay $(\mathrm{p}=0.70)$.

\section{Language}

Scores on the BNT improved significantly between the baseline and the 3 month evaluations and between the baseline and the 12 month evaluations $(\mathrm{p}=0.01$ and $\mathrm{p}=0.001$, respectively). Time accounted for $40 \%$ of the variance in BNT scores, which is a large effect size. The 3 month and 12 month scores on the BNT did not change significantly $(p=0.29)$ and the timexlesion side interaction effect was not significant $(p=0.75)$.

With the exclusion of the three patients with adverse events on postoperative imaging studies, verbal fluency scores on the COWAT showed an overall non-significant trend for decline over time $(p=0.08)$. When these three patients were included in the analyses, verbal fluency showed a significant decline between the baseline and 3 month evaluations and between the baseline and 12 month evaluations $(p=0.04$ and $p=0.03$, respectively). The 3 month and 12 month scores on the COWAT did not differ significantly $(p=0.77)$ and the timexlesion side interaction effect was nonsignificant $(p=0.25)$. Time accounted for $14 \%$ of the total variance in COWAT scores, which is a small effect size.

\section{Visuospatial}

Visuospatial organisation ability as measured by the Hooper improved significantly between the baseline and the 3 month evaluations and between the baseline and 12 month evaluations $(\mathrm{p}=0.02$ and $\mathrm{p}=0.05$, respectively). Time accounted for $15 \%$ of the variance in Hooper scores, which is a small effect size. There was not a significant difference between the 3 month and 12 month evaluations $(p=0.99)$ and the timexlesion side interaction effect was not significant $(p=0.99)$.

\section{Information processing}

SDMT and trails A did not show significant differences across time periods (SDMT: $\mathrm{p}=0.85$; trails $\mathrm{A}: \mathrm{p}=0.77$ ) and the timexlesion side interaction was not significant for either measure (SymDigit: $\mathrm{p}=0.74$; trails $\mathrm{A}: \mathrm{p}=0.12$ ). Patients did not show any significant changes

Table 5 Repeated measures ANOVA results for neuropsychological measures for total sample $(n=42) t^{\star}$

\begin{tabular}{|c|c|c|c|c|c|c|c|c|c|c|c|}
\hline \multirow[b]{2}{*}{ Measure } & \multicolumn{3}{|l|}{ Pre-PVP } & \multicolumn{3}{|c|}{3 month Post-PVP } & \multirow{2}{*}{$\begin{array}{l}\text { Pre to } 3 \\
\text { months } \\
\text { p Value }\end{array}$} & \multicolumn{3}{|c|}{12 month Post-PVP } & \multirow{2}{*}{$\begin{array}{l}\text { Pre to } 12 \\
\text { months } \\
\text { p Value }\end{array}$} \\
\hline & $\begin{array}{l}\text { Right } \\
\text { Mean (SD) }\end{array}$ & $\begin{array}{l}\text { Left } \\
\text { Mean (SD) }\end{array}$ & $\begin{array}{l}\text { Total } \\
\text { Mean (SD) }\end{array}$ & $\begin{array}{l}\text { Right } \\
\text { Mean (SD) }\end{array}$ & $\begin{array}{l}\text { Left } \\
\text { Mean (SD) }\end{array}$ & $\begin{array}{l}\text { Total } \\
\text { Mean (SD) }\end{array}$ & & $\begin{array}{l}\text { Right } \\
\text { Mean (SD) }\end{array}$ & $\begin{array}{l}\text { Left } \\
\text { Mean (SD) }\end{array}$ & $\begin{array}{l}\text { Total } \\
\text { Mean (SD) }\end{array}$ & \\
\hline \multicolumn{12}{|l|}{ Mental status: } \\
\hline MMSE (0-30) & $28.4(1.5)$ & $27.7(2.3)$ & $28.0(.34)$ & $27.9(1.8)$ & $28.1(2.3)$ & $28.0(0.36)$ & 0.94 & $28.1(2.1)$ & $27.8(2.3)$ & $28.0(0.37)$ & 0.71 \\
\hline \multicolumn{12}{|l|}{ Verbal learning: } \\
\hline $\begin{array}{l}\text { CVLT Total } 1-5 \ddagger \\
(0-80)\end{array}$ & $41.4(11.6)$ & $41.6(11.0)$ & $41.4(2.1)$ & $39.2(11.0)$ & $37.1(12.6)$ & $36.5(2.2)$ & $0.004 \downarrow$ & $39.8(14.1)$ & $41.0(10.4)$ & $40.3(2.2)$ & 0.42 \\
\hline $\begin{array}{l}\text { CVLT Long delay } \\
(0-16)\end{array}$ & $8.33(2.9)$ & $8.08(3.2)$ & $8.18(.58)$ & $8.15(4.0)$ & $7.43(3.7)$ & $7.37(0.68)$ & 0.10 & $8.09(3.8)$ & $7.67(3.9)$ & $7.81(0.73)$ & 0.34 \\
\hline \multicolumn{12}{|l|}{ Language: } \\
\hline BNT (0-60) & $52.8(6.7)$ & $52.3(8.0)$ & $52.3(1.4)$ & $54.8(4.6)$ & $53.7(5.7)$ & $54.0(1.0)$ & $0.01 \uparrow$ & $55.3(7.6)$ & $55.1(7.6)$ & $54.8(1.4)$ & $0.001 \uparrow$ \\
\hline COWAT & $32.2(10.9)$ & $32.8(9.9)$ & $32.5(1.7)$ & $31.6(9.1)$ & $28.3(8.8)$ & $29.9(1.5)$ & $0.04 \downarrow$ & $30.2(11.4)$ & $29.0(12.1)$ & $29.6(1.9)$ & $0.03 \downarrow$ \\
\hline COWATS & $33.3(10.6)$ & $32.6(10.0)$ & $32.8(1.1)$ & $32.8(8.5)$ & $28.7(9.0)$ & $29.9(1.9)$ & 0.07 & $31.0(11.5)$ & $29.8(12.2)$ & $30.2(1.9)$ & 0.06 \\
\hline \multicolumn{12}{|l|}{ Visuospatial: } \\
\hline Hooper (0-30) & $23.1(3.3)$ & $23.1(4.5)$ & $23.1(0.70)$ & $24.1(3.8)$ & $24.1(4.2)$ & $24.1(0.68)$ & $0.02 \uparrow$ & $24.1(3.8)$ & $24.0(4.3)$ & $24.1(0.69)$ & $0.05 \uparrow$ \\
\hline \multicolumn{12}{|l|}{ Info processing: } \\
\hline SDMT & $37.8(11.4)$ & $34.0(11.8)$ & $35.9(2.0)$ & $36.2(11.7)$ & $34.6(12.0)$ & $35.4(2.0)$ & 0.74 & $36.9(8.4)$ & $35.4(12.9)$ & $36.1(2.0)$ & 0.89 \\
\hline Trails A & $47.8(24.6)$ & $55.5(29.8)$ & $51.6(4.9)$ & $53.1(26.9)$ & $46.8(18.2)$ & $49.8(3.7)$ & 0.61 & $50.8(22.6)$ & $54.4(33.4)$ & $52.5(5.3)$ & 0.85 \\
\hline \multicolumn{12}{|l|}{ Executive functions: } \\
\hline Stroop interference $\ddagger$ & $-0.904(5.9)$ & $-0.309(8.7)$ & $-0.606(1.3)$ & $-3.72(6.9)$ & $0.629(8.7)$ & $-1.54(1.4)$ & 0.41 & $1.08(6.9)$ & $3.77(8.0)$ & $2.43(1.3)$ & $0.02 \uparrow$ \\
\hline Trails B & $200.6(189)$ & $154.4(107)$ & $177.5(23)$ & $159.7(81)$ & $168.8(130)$ & $164.8(20)$ & 0.57 & $153.6(66)$ & $175.1(165)$ & $165.5(25)$ & 0.61 \\
\hline WCST total errors $\ddagger$ & $61.5(15.9)$ & $57.3(16.5)$ & $58.8(2.9)$ & $58.5(22.8)$ & $53.8(20.2)$ & $57.4(4.0)$ & 0.58 & $50.1(21.8)$ & $52.8(22.4)$ & $50.7(3.8)$ & $0.01 \uparrow$ \\
\hline \multicolumn{12}{|l|}{ Affective functioning: } \\
\hline BDIऽ (0-63) & $13.2(9.0)$ & $8.90(5.6)$ & $11.1(1.1)$ & $9.15(7.0)$ & $7.28(5.5)$ & $8.21(1.0)$ & $0.02 \uparrow$ & $7.23(5.6)$ & $8.69(7.2)$ & $7.96(1.1)$ & $0.01 \uparrow$ \\
\hline
\end{tabular}

†No significant differences between right and left pallidotomy patients on neuropsychological variables; $\ddagger$ Significant improvement between 3 month and 12 months evaluations $(\mathrm{p}<.05)$; ${ }^{\star}$ Results did not change with the exclusion of three patients with postoperative adverse events unless otherwise noted; $\ C O W A T$ scores excluding three patients with postoperative adverse events; Strend for difference between right and left PVP ( $>0.05$ ); Bold=Significant contrasts with significant time main effect $(\mathrm{p}<0.05) ; \uparrow=$ improvement; $\downarrow=$ decline.

$\mathrm{BDI}=$ Beck depression inventory; $\mathrm{BNT}=$ Boston naming test; $\mathrm{COWA}=$ controlled oral word association test; $\mathrm{CVLT}=\mathrm{California}$ verbal learning test, trials $1-5$, long delay; Hooper=Hooper visual organization test; $\mathrm{MMSE}=$ mini mental state examination; Stroop=Stroop colour word test, interference; WCST=Wisconsin card sorting test, total errors. 
Table 6 Repeated measures ANOVA results for significant neuropsychological measures by motor impairment

\begin{tabular}{|c|c|c|c|c|c|c|}
\hline \multirow[b]{2}{*}{ Measure } & \multicolumn{2}{|l|}{ Pre-PVP } & \multicolumn{2}{|c|}{3 month post-PVP } & \multicolumn{2}{|c|}{12 month post-PVP } \\
\hline & $\begin{array}{l}\text { Mild/mod. } \\
\text { Mean }(S D)\end{array}$ & $\begin{array}{l}\text { Severe } \\
\text { Mean (SD) }\end{array}$ & $\begin{array}{l}\text { Mild/mod. } \\
\text { Mean (SD) }\end{array}$ & $\begin{array}{l}\text { Severe } \\
\text { Mean (SD) }\end{array}$ & $\begin{array}{l}\text { Mild/mod. } \\
\text { Mean (SD) }\end{array}$ & $\begin{array}{l}\text { Severe } \\
\text { Mean (SD) }\end{array}$ \\
\hline \multicolumn{7}{|l|}{ Verbal learning: } \\
\hline CVLT Total $1-5(0-80)^{\star}$ & $41.3(10.6)$ & $42.0(14.1)$ & $37.2(12.4) \dagger$ & $32.1(10.4) \dagger$ & $39.5(11.2)$ & $44.4(14.0)$ \\
\hline \multicolumn{7}{|l|}{ Language: } \\
\hline BNT (0-60) & $53.1(7.2)$ & $49.4(8.8)$ & $54.0(5.6)$ & $52.9(5.6)$ & $55.5(7.4)$ & $52.1(8.9)$ \\
\hline COWAT & $33.6(10.1)$ & $29.2(10.0)$ & $29.2(9.6)$ & $29.7(6.4)$ & $29.8(12.4)$ & $27.7(9.6)$ \\
\hline \multicolumn{7}{|l|}{ Visuospatial: } \\
\hline Hooper (0-30) & $24.2(3.5)$ & $19.4(4.5)$ & $24.9(3.6)$ & $20.9(4.0)$ & $24.9(3.7)$ & $21.0(4.2)$ \\
\hline \multicolumn{7}{|l|}{ Executive functions: } \\
\hline Stroop interference & $-0.422(8.0)$ & $-0.75(7.7)$ & $-0.605(8.7)$ & $-1.12(7.3)$ & $3.05(8.0)$ & $2.56(6.8)$ \\
\hline WCST Total errors & $58.0(17.2)$ & $55.0(8.2)$ & $56.8(22.2)$ & $55.0(19.7)$ & $49.4(21.8)$ & $60.5(35.7)$ \\
\hline
\end{tabular}

*Time $\times$ motor impairment effect, $\mathrm{p}<0.05 ; \mathrm{BNT}=$ Boston naming test; COWA=controlled oral word association test; CVLT $=$ California verbal learning test, Trials $1-5$; Hooper $=$ Hooper visual organisation test; Stroop=Stroop colour word test, interference; WCST $=$ Wisconsin card sorting test, total errors.

in their information processing abilities after surgery.

\section{Executive functioning}

The total number of errors on the WCST decreased between the baseline and 12 month evaluations and the 3 month and 12 month evaluations ( $p=0.01$ and $p=0.04$, respectively). The timexlesion side interaction effect was not significant for the WCST total error score $(\mathrm{p}=0.45)$. Time accounted for $20 \%$ of the variance in WCST total error scores, which is a small effect size. Patients with right or left PVP also demonstrated delayed improvement in the ability to resist interference from competing stimuli as measured by the Stroop test between the pre-PVP and 12 month evaluations and between the 3 month and 12 month evaluations ( $p=0.01$ and $p=0.01$, respectively). The timexlesion side interaction effect was not significant for the Stroop test $(p=0.26)$. Time accounted for $21 \%$ of the variance in Stroop interference scores, which is a small effect size. Time to completion of trails B, WCST categories, and WCST perseverative errors did not show significant changes over time (trails B: $\mathrm{p}=0.82$; WCST categories: $\mathrm{p}=0.42$; WCST perseverative errors: $p=0.21$ ) and the timexlesion side interaction effect was not significant for any of these variables (trails $\mathrm{B}$ : $\mathrm{p}=0.32$; WCST categories: $\mathrm{p}=0.29$; WCST perseverative errors: $\mathrm{p}=0.68$ ).

HEMISPHERE SPECIFIC CHANGES

No significant main effects for lesion side or timexlesion side interaction effects were found for any of the neuropsychological measures. The patients with right or left PVP did not differ on any neuropsychological measure between the preoperative and follow up evaluations or between the 3 month and 12 month assessments. A second series of repeated measures ANOVAs were performed to test the interaction of sex and lesion side on neuropsychological outcome. The analyses did not show any significant $s e x \times$ lesion side interactions. Male and female patients with right or left PVP did not differ significantly on any neuropsychological variables.

AFFECTIVE FUNCTIONING

Scores on the BDI improved significantly between the baseline and 3 month post-PVP evaluations and the baseline and 12 month fol- low up evaluations $(\mathrm{p}=0.02$ and $\mathrm{p}=0.02$, respectively), but not between the 3 month and 12 month evaluations $(p=0.84)$. The timexlesion side interaction showed a nonsignificant trend $(p=0.07)$. In general, the improvement in BDI scores was unrelated to any alteration in antidepressant drug regimen. When the three patients with adverse events on postoperative imaging studies were excluded from the analysis, the timexlesion side interaction was not found to be significant $(\mathrm{p}=0.14$; table 5).

RELATION BETWEEN PREOPERATIVE MOTOR SYMPTOM SEVERITY AND COGNITIVE OUTCOME To assess the effect of preoperative level of motor symptom severity on cognitive outcome, a repeated measures ANOVA with time (baseline, 3 months, 12 months) as the within subject factor and motor impairment (severe versus mild to moderate) as the between subject factor was conducted for each of the cognitive variables that demonstrated a significant difference at either 3 months or 12 months post-PVP. The patients were divided into two subgroups based on their preoperative Hoehn and Yahr scores both in the on and off states. Patients who were severely impaired before PVP (Hoehn and Yahr on $\geqslant 3$ and Hoehn and Yahr off $\geqslant 4$, seven patients) were compared with patients with less severe preoperative motor impairments ( Hoehn and Yahr on $\leqslant 2$ and Hoehn and Yahr off $\leqslant 3,28$ patients). The mild to moderately motor impaired patients did not differ from the severely impaired patients on any demographic variable $(p>0.05)$. As expected, the severely impaired patients showed significantly worse preoperative neurology scores while in on and off states $(p<0.05)$. Table 6 shows the means (SD) of each neuropsychological variable for the severely impaired and mildly to moderately impaired groups on the preoperative, 3 month, and 12 month follow up evaluations. A significant time $\times$ motor impairment interaction was found for CVLT Total 1-5 $(F(2,32)=3.19$, $\mathrm{p}=0.05)$. Post hoc analyses showed that the severely impaired group had lower scores on the CVLT at the 3 month evaluation than the mild to moderate group $(\mathrm{p}=0.05)$. However, patients with severe preoperative motor impairments scored higher than those patients with mild to moderate preoperative impairments on 


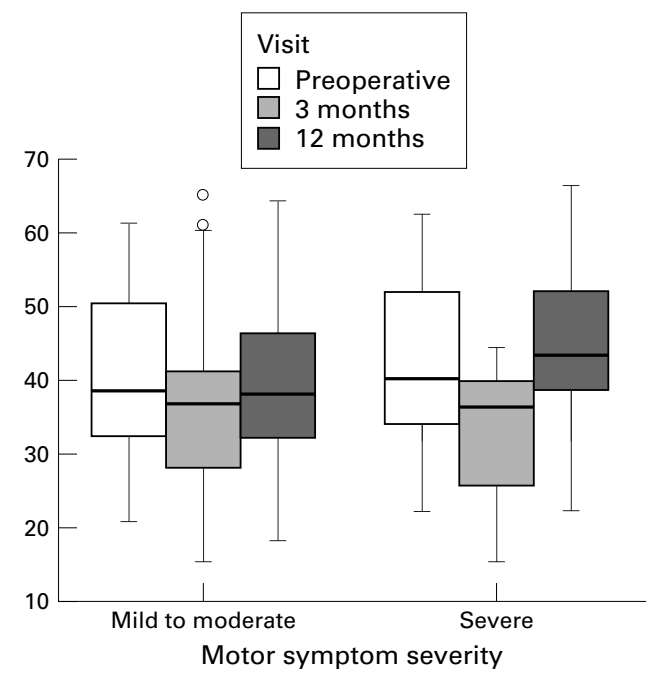

Impairment of verbal learning before and after pallidotomy.

verbal learning at the 12 month evaluation, with scores for both groups returning to baseline 1 year after surgery $(p=0.05$; figure). No other significant timexmotor impairment interaction effects were found for any of the other neuropsychological variables. Patients with mild to moderate preoperative motor impairment did not differ on cognitive outcome from the patients with severe preoperative motor impairment, with the exception of the CVLT total score.

RELATION BETWEEN PREOPERATIVE COGNITIVE FUNCTIONING AND COGNITIVE OUTCOME

To assess the effect of preoperative cognitive functioning on neuropsychological outcome, a repeated measures ANOVA with time (baseline, 3 months, 12 months) as the within subjects factor and mental status (impaired $v$ intact) as the between subjects factor was conducted for each of the neuropsychological variables that showed a significant change from baseline at either 3 months or 12 months postPVP. The sample was divided into two subgroups based on their preoperative MMSE scores. Patients who registered preoperative impairment on the MMSE (MMSE $\leqslant 26$ ) were compared with patients in the normal range (MMSE $\geqslant 27) .{ }^{36}$ No significant time $\times$ mental status interaction effects were found for any of the neuropsychological variables. Patients with intact preoperative mental status did not differ significantly on cognitive outcome from patients who showed below expected mental status scores preoperatively.

\section{Discussion}

This study of 42 patients with advanced Parkinson's disease who underwent preoperative, 3 month post-PVP, and 12 month post-PVP evaluations is the largest long term follow up study of cognitive outcome after PVP reported to date. While in the off state, all patients showed significant improvements in motor symptoms 3 months post-PVP, with these improvements being maintained by $95 \%$ of the patients for up to 1 year after surgery. These motor improvements were achieved while maintaining patients on essentially the same levodopa dosage as before PVP. Therefore, the motor and cognitive changes after the surgery are not likely attributable to increases in medication regimens. The neuropsychological testing was conducted during the patient's best on state to optimise patient performance and to allow for completion of the neuropsychological testing battery. Consequently, conclusions drawn from the results cannot be generalised to a patient's cognitive performance during the off state.

\section{SUMMARY OF NEUROPSYCHOLOGICAL}

IMPROVEMENTS

Patients with right or left PVP showed significant improvements in confrontational naming and visuospatial organisation up to 1 year after PVP. Executive functioning tasks produced an inconsistent trend toward improvement 12 months after PVP. Whereas performance did not change over time on trails $\mathrm{B}$, patients were better able to resist interference from competing stimuli on the Stroop test and made fewer errors on a task of hypothesis generation. It is difficult to determine the clinical significance of these improvements without a clear consensus of the influence of practice on these measures. Consistent with previous reports, patients reported lower levels of depressive symptoms after surgery. ${ }^{911}$ Patients reported minimal levels of depressive symptoms after PVP, which was an improvement from the mild symptoms they reported before surgery.

SUMMARY OF NEUROPSYCHOLOGICAL DECLINES Our patients showed a transient decline in learning verbal material 3 months post-PVP, with this deficit returning to baseline scores by the 12 month evaluation. This finding of cognitive decline after unilateral PVP is generally consistent with previous reports of neuropsychological outcome after PVP. ${ }^{11}{ }^{12}$ The finding of transient declines in learning verbal material may be clinically significant to patients after PVP. Memory compensation techniques (for example, memory journals, computerised medication prompts) may be initiated before surgery to prepare patients for these transient memory problems after surgery.

The analyses were run excluding the two patients with a previous neurosurgical history and the three patients with adverse events after surgery. When the two patients who had had a previous neurosurgical procedure were excluded from the analyses, the findings did not change. Thus, these patients were included in the current analyses. When three patients who had adverse events on postoperative imaging studies were excluded from the analysis, a decline in verbal fluency performance after PVP was not found to be significant. This finding suggests that larger lesions that may have encroached on adjacent structures (for example, internal capsule, putamen) may affect cognitive outcome after PVP. Patients with satisfactory lesion placement and without adverse events on postoperative imaging studies did not show a decline in verbal fluency after PVP. 
When Baron et al excluded the data from two patients with small frontal subdural haematomas, none of their neuropsychological variables showed a significant change at 3 or 12 months post-PVP. ${ }^{8}$ Our current findings, along with those of Baron et al, highlight the need to investigate the relation between the specific nuclei and fibre bundles interrupted after PVP and cognitive outcome. ${ }^{8}$

Our results differ from previous reports in that the expected hemisphere-specific decline in verbal fluency for patients with left PVP compared with patients with right PVP was not found in the present study. Verbal fluency has been shown in patients with head injury to have high sensitivity to frontal lobe damage regardless of the side of lesion. ${ }^{37}$ The overall lack of hemisphere-specific cognitive changes in a patient population of adequate size to detect differences suggests that cognitive deficits after PVP may be due to changes in the basal ganglia thalamocortical circuitry regardless of the side of lesion placement. However, the lack of findings may also be due to limitations in the scope of the test battery. Future long term outcome research utilising more comprehensive neuropsychological test batteries with repeated measures multivariate analyses is needed to replicate and validate the current findings.

The vast literature on the dissociation in performance between verbal fluency and confrontational naming allows for further investigation of the cognitive processes that may be negatively affected by PVP. When the total sample was included in the analyses, the current study found a significant decline in verbal fluency and a significant improvement in confrontational naming 12 months post-PVP. Firstly, this dissociation suggests that the decline in verbal fluency is not likely due to word finding difficulties, which the BNT often shows. ${ }^{38}{ }^{39}$ Secondly, Huff argued that a dissociation between these tasks may be due to the automatic processing required by the BNT compared with the effortful processing required by the verbal fluency task. ${ }^{40}$ Thirdly, Margolin et al argued that the tasks differ in the type of verbal processing that is required, with a decline in verbal fluency suggesting phonological processing dysfunction, rather than semantic processing, which is required by the naming task. ${ }^{41}$ Fourthly, the verbal fluency task emphasises response speed whereas the naming task is not timed, suggesting that the dissociation is related to general information processing speed abilities. Fifthly, whereas verbal fluency has been shown to be sensitive to frontal lobe damage and mental flexibility impairment, naming is dependent on frontal and temporal lobe functioning and memory retrieval. ${ }^{42}{ }^{43}$ Declines in verbal fluency after PVP may be due to failures in several cognitive areas including effortful processing, lexical processing, general speed of information processing, and mental flexibility. ${ }^{44}{ }^{45}$ The total number of words generated from the verbal fluency task (the current measure of analysis) does not provide information on these specific underlying components of the task. Future research into these components, including semantic versus lexical processing, timed versus untimed responding, and clustering (for example, generating words within subcategories) versus switching (shifting between subcategories), may lead to a clearer understanding of the specific cognitive processes affected by PVP. ${ }^{46}$

Patients with severe versus mild to moderate preoperative motor impairment and those with impaired versus intact preoperative mental status were investigated separately to further clarify the efficacy of PVP for subgroups of patients with Parkinson's disease. With the exception of a transient decline in verbal learning performance at 3 months post-PVP, patients with severe motor impairment did not differ on cognitive outcome from patients with less severe preoperative motor impairment. Likewise and consistent with the findings of Riordan et al patients with impaired preoperative mental status did not differ on cognitive outcome from patients with intact mental status. ${ }^{11}$ Patients with varying motor symptom severity and mental status received equal benefit from PVP with minimal changes in cognitive outcome. It has been stated that "dementia is widely accepted as a contraindication" for PVP. ${ }^{14}$ We think that patients with mild to moderate dementia with MMSE scores above 20 should not be denied surgery automatically. Patients with more severe dementia, on the other hand, are not suitable candidates for surgery as they might not gain sufficient benefit in daily activities even though their motor symptoms might be improved. Future research considering the utility of preoperative cognitive status as an exclusion criterion for PVP is needed for a consensus to be reached.

Our investigation attempted to address several methodological limitations present in published reports of the neuropsychological outcome after PVP, including sample size, follow up periods, attrition rates, and practice effects, as well as to correlate accurate placement of the lesion and the presence of additional adverse events on postoperative imaging studies with outcome. By contrast with several preliminary reports, the present study investigated a large sample of patients who each received two follow up evaluations; thus allowing for the use of repeated measures multivariate statistical analysis to assess significant differences over time and between right and left PVP. ${ }^{8}{ }^{10}{ }^{15}$ Furthermore, the current 12 month follow up evaluation of cognitive outcome was based on an adequate sample size to draw more definite conclusions regarding the long-term efficacy of the surgery.

The reporting of rates of attrition in the sample, along with the differences between the study participants and those patients who were lost to follow up, aids in describing the sample and allows for more specific comparisons across sites. To date, attrition rates have not been considered in the pallidotomy literature. The moderate attrition in the current sample points out the main limitation of the study and highlights the need to report rates of attrition in future studies. Further analysis showed that 
most of those patients who were lost to follow up were restricted by long travel distances and elected to receive follow up evaluations closer to home. The significant differences found between the study participants and those who dropped out may pose a threat to the external validity of the study. Whereas study participants did not differ presurgically from those who dropped out either with motor problems or in their ability to perform ADLs while in the off state, study participants were significantly less impaired in motor function and more able to perform ADLs independently while on than those who did not return for both follow up evaluations. Thus, the interpretation of the current findings may be limited to patients who demonstrate distinct on and off states, with mild to moderate impairments while on and more severe impairments while in the off state. The presurgical differences between the study participants and those who dropped out may become more salient after surgery; therefore, home visits may need to be implemented to obtain follow up data on a larger number of patients and to help reduce attrition rates.

Cognitive improvements were found for several tasks in which alternate forms were not available, raising the question of the role of practice effects on outcome. However, some of these measures have been shown to be relatively resistant to the effects of practice. The Hooper test and the BNT have high testretest reliabilities without a significant shift in scores after repeated administrations (Hooper, 0.86; BNT,0.94)..$^{45}$ Although experience with the Stroop test does affect performance, this executive functioning measure is more resistant to practice effects than the WCST, which has a specific, easily conceptualised solution. ${ }^{48}{ }^{49}$ However, the Stroop test requires a timed verbal response; therefore, an improvement in performance may be in part secondary to the marked motor improvement seen after surgery. The SDMT and trails A and $\mathrm{B}$, which are tests with a prominent motor component, failed to show the expected improvement with practice, which may be evidence of a negative outcome. On the other hand, rather than showing the expected practice effects on the COWAT, patients showed a decline in verbal fluency performance, suggesting that the main effect of time on COWAT scores may have been underestimated in our study. Although the effects of practice cannot be ruled out in the current study, it is unlikely that the demonstrated cognitive improvements after PVP are due entirely to previous experience with the measures. Alternative methods for contending with practice effects in serial assessment, such as non-surgical comparison groups and statistical methods (for example, growth curves and change scores), need to be employed.

Due to the lack of a non-surgical comparison group, we were unable to consider the role of cognitive decline as a component of the natural course of Parkinson's disease after PVP. With prevalence estimates of dementia ranging from $10 \%$ to $40 \%$ in patients with Parkinson's disease, PVP superimposes an intervention on a progressive and highly variable disease. ${ }^{50-52}$ To determine the proportion of changes after PVP that are related exclusively to the surgery and those that are related to natural cognitive decline due to the progressive nature of the disease, a systematic study including a nonsurgical comparison group and a more comprehensive neuropsychological battery would be an invaluable addition to the literature.

Nonetheless, the current findings suggest that male and female patients with right or left PVP with varying preoperative mental status and motor symptom severity receive equal benefit from PVP for up to 1 year after surgery. Although three patients showed subtle cognitive decline subsequent to postoperative adverse events, these patients received considerable motor benefit from the surgery allowing them more independence in their ability to perform ADLs. In the largest long term follow up study of PVP reported to date, the cognitive changes after unilateral PVP are minimal compared with the robust improvements seen in motor function.

We thank James Song for his valuable statistical advice for the manuscript. This work was supported in part by an NIH Postdoctoral Medical Rehabilitation Research Training Grant HDO7465.

1 Dogali M, Fazzini E, Kolodny E, et al. Stereotactic ventral pallidotomy for Parkinson's disease. Neurology 995;45:753-61.

2 Kishore A, Turnbull IM, Snow BJ, et al. Efficacy, stability and predictors of outcome of pallidotomy for Parkinson's disease. Six month follow-up with additional 1-year observations. Brain 1997;120:729-37.

3 Lang AE, Lozano AM, Montgomery E, et al. Posteroventral medial pallidotomy in advanced Parkinson's disease. $N$ Engl f Med 1997;337:1036-42.

4 Vitek JL, Bakay RAE, Delong MR. Microelectrode-guided pallidotomy for medically intractable Parkinson's disease. Adv Neurol 1997;74:183-98.

5 Fazzini E, Dogali M, Sterio D, et al. Stereotactic pallidotomy for Parkinson's disease: a long term follow up of unilateral pallidotomy. Neurology 1997;48:1273-7.

6 Kopyov O, Jacques D, Duma C, et al. Microelectrodeguided posteroventral medial radiofrequency pallidotomy for Parkinson's disease. $\mathcal{F}$ Neurosurg 1997;87:52-9.

7 Lozano AM, Lang AE, Galvez-Jimenez N, et al. Effects of GPi pallidotomy on motor function in Parkinson's disease.
Lazing Lancet 1995;346:1383-7.

8 Baron MS, Vitek JL, Bakay RAE, et al. Treatment of advanced Parkinson's disease by posterior GPi pallidotomy: 1 year results of a pilot study. Arch Neurol 1996;40:355-66.

9 Masterman D, DeSalles A, Baloh RW, et al. Motor, cognitive, and behavioral performance following unilateral ventroposterior pallidotomy for Parkinson disease. Arch Neurol 1998;55:1201-8.

10 Soukup VM, Ingram F, Schiess MC, et al. Cognitive sequelae of unilateral posteroventral pallidotomy. Arch Neurol 1997;54:947-50

11 Riordan HJ, Flashman LA, Roberts DW. Neurocognitive and psychosocial correlates of ventroposterolateral pallidotomy surgery in Parkinson's disease. Neurosurg Focus j/mar97/2-3-7.html.

12 Trepanier LL, Saint-Cyr JA, Lozano AM, et al. Neuropsychological consequences of posteroventral pallidotomy for the treatment of Parkinson's disease. Neurology 1998;51:207-15.

13 Rettig GM, Lai EC, Grossman R, et al. Neuropsychological evaluation of patients with Parkinson's disease before and after pallidal surgery. In: Krauss JK, Grossman R, Jankovic J, eds. Pallidal surgery for the treatment of Parkinson's disease and movement disorders. Phildelphia: Lippencott-Raven, 1998:211-31.

14 Scott R, Gregory R, Hines N, et al. Neuropsychological, neurological and functional outcome following pallidotomy for Parkinson's disease. Brain 1998;121:659-75.

15 Uitti RJ, Wharen REJr, Turk MF, et al. Unilateral pallidotomy for Parkinson's disease: comparison of outcome in younger versus elderly patients. Neurology 1997;49:1072-7.

16 York MK, Levin HS, Grossman R. Neuropsychological outcome following unilateral pallidotomy [review]. Brain 1999;122:2209-20.

17 Lang AE. Clinical rating scales and videotape analysis. In: Koller WC, Paulson GW, eds. Therapy of Parkinson's disease. New York: Marcel Dekker, 1990:3-30. 
18 Lai EC, Krauss JK. Indications for pallidal surgery for Parkinson's disease, In: Krauss JK, Grossman R, eds. Pallidal surgery for the treatment of Parkinson's disease and movement

disorders. Philadelphia: Lippincott-Raven, 1998:113-20.
Folstein M, Folstein S, McHugh P. Mini-mental state: practical guide for grading the mental state of patients for the clinician. F Psychiatry Res 1975;12:189-98.

20 Schaltenbrand G, Wahren P. Atlas for stereotaxy of the human brain. Stuttgart: Theime, 1977.

21 Krauss JK, Grossman R. Operative techniques for pallida surgery, In: Krauss JK, Grossman R, eds. Pallidal surgery for the treatment of Parkinson's disease and movement disorders. Philadelphia: Lippincott-Raven, 1998:121-33.

22 Langston JW, Widner H, Goetz CG, et al. Core assessment program for intrace

Disord 1992; 7:2-13. Drown RG, Marsden CD. Cognit disease: from description to theory. Trends Neurosci 1990;13:21-9.

24 Dubois B, Boller F, Pillon B, et al. Cognitive deficits in Parkinson's disease. In: Boller F, Grafman J, eds. Handbook of neuropsychology. 5th ed. Amsterdam: Elsevier, 1991:195240.

25 Delis D, Kramer J, Kaplan E, et al. The California verbal learning test: adult version. San Antonio, TX: The Psychological Corporation, 1987

26 Kaplan E, Goodglass H, Weintraub S. The Boston naming test. 2nd ed. Philadelphia, PA: Lea and Febiger, 1983.

27 Benton A, Hamsher K. Multilingual aphasia examination. 2nd ed. Iowa City, IA: University of Iowa, 1989.

28 Hooper H. Hooper visual organization test. Los Angeles, CA: Western Psychological Services, 1983.

29 Bornstein RA. Normative data on selected neuropsychological measures from a nonclinical sample. $\mathcal{F}$ Clin Psychol 1985;41:651-9.

30 Smith A. Symbol digit modalities test manual (revised). Los Angeles, CA: Western Psychological Services, 1982.

31 Heaton R, Chelune G, Talley J, et al. Wisconsin card sorting test manual revised and expanded. Odessa, FL: Psychological test manual revised and expanded.

32 Golden J. Stroop color and word test. Chicago, IL: Stoelting, 1978.

33 Beck A. Beck depression inventory manual. San Antonio, TX Psychological Corporation, 1978.

34 Krauss JK, Desaloms JM, Lai EC, et al. Microelectrodeguided postereoventral pallidotomy for treatment of Parkinson's disease: postoperative magnetic resonance imaging analysis. F Neurosurg 1997;87:358-67.

35 Taylor A, Saint-Cyr JA, Lang AE. Frontal lobe dysfunction in Parkinson's disease: the cortical focus of neostriatal outflow. Brain 1986;190:845-83.
36 Lemsky C, Smith G, Malec J, et al. Identifying risk for functional impairment using cognitive measures: an application of CART modeling. Neuropsychology 1996;10:368-75.

37 Miceli G, Caltagirone C, Gainotti G, et al. Neuropsychological correlates of localized cerebral lesions in nonaphasic brain-damaged patients. F Clin Neuropsychol 1981;3:53-63.

38 Lezak MD. Emotional impact of cognitive inefficiencies in mild head trauma. 7 Clin Exp Neuropsychol 1991;13:23.

39 Lezak MD, Whitman R, Bourdette D. Emotional impact of cognitive inefficiencies in multiple sclerosis. f Clin Exp Neuropsychol 1990;8:149.

40 Huff FJ. Language in normal aging and age-related neurological diseases. In: Nebes RD, Corkin S, eds. Handbook of neuropsychology. Amsterdam: Elsevier, 1990.

41 Margolin DI, Pate DS, Friedrich FJ, et al. Dysnomia in dementia and stroke patients: different underlying cognitive deficits. F Clin Exp Neuropsychol 1990;12:597-612.

42 Janowsky J, Shimamura A, Kritchevsky M, et al. Cognitive impairment following frontal lobe damage and its relevance to human amnesia. Behav Neurosci 1989;103:548-60.

43 Knopman D, Selnes O, Niccum N, et al. Recovery of naming in aphasia: relationship to fluency, comprehension and CT findings. Neurology 1984;34:1461-70.

44 Auriacombe S, Grossman M, Carvell S, et al. Verbal fluency deficits in Parkinson's disease. Neuropsychology 1993;7: 182-92.

45 Lezak MD. Neuropsychological assessment. 2nd ed. New York: Oxford University Press, 1995:115.

46 Troyer AK, Moscovitch M, Winocur G, et al. Clustering and switching on verbal fluency tests in Alzheimer's and Parkinson's disease. F Int Neuropsychol Soc 1998;4:137-43.

47 Sawrie S, Chelune G, Naugle R, et al. Empirical methods for assessing meaningful change following epilepsy surgery. $\mathcal{F}$ Int Neuropsychol Soc 1996;2:556-64.

48 Connor A, Franzen M, Sharp B. Effects of practice and differential instructions on Stroop performance. Int $\mathcal{f}$ Clin Neuropsychol 1988;10:1-4.

49 Dodrill CB, Troupin AS. Effects of repeated administrations of a comprehensive neuropsychological test battery among chronic epileptics. I Nerv Ment Disease 1975;161: $185-90$.

50 Brown RG, Marsden CD. How common is dementia in Parkinson's disease? Lancet 1984;ii:1262-5.

51 Cummings JL. The dementias of Parkinson's disease: prevalence, characteristics, neurobiology, and comparison with dementia of the Alzheimer type. Eur Neurol 1988;28(suppl 1):15-23.

52 Taylor A, Saint-Cyr JA, Lang AE. Dementia prevalence in Parkinson's disease. Lancet 1985;1:1037. 